\title{
Online Accreditation Process and DAK Management Information System (DAK-MIS) General Directorate for Accreditation of Kosovo
}

\author{
Ibush Luzha ${ }^{1, *}$, Anni Dasho Sharko² \\ ${ }^{1}$ Ministry of Trade and Industry, Str. Muharrem Fejza, n.n. Hospital Square Pristine, Kosovo \\ ${ }^{2}$ Department of Informatics, Math's and Statistic, Economic and Information Technology Faculty, European University of Tirana, Albania
}

Copyright $(2017$ by authors, all rights reserved. Authors agree that this article remains permanently open access under the terms of the Creative Commons Attribution License 4.0 International License

\begin{abstract}
General Directorate for Accreditation of Kosovo (DAK) is the only National Accreditation Body in the Republic of Kosovo, based on Law No. 05 / L-117 approved in the Kosovo Assembly on 20.12.2016 and published in the Official Newspaper of the Republic of Kosovo, No. 2/12 January 2017, in accordance with international standards, assesses technical competences of the Conformity Assessment Bodies (CAB)s that deals with activities such as: testing, calibration, certification and inspection both in public and private sector. Till now application for accreditation process and all other procedures for accreditation of CABs are carried out manually, and all the documents of the application and the receipt of the certificate of accreditation are conducted in the offices of DAK manually not using an appropriate Management Information System, DAK-MIS System. Through DAK Management Information System (DAK-MIS), customers will get and proceed all needed documents online, starting from: Application for accreditation, Application review, Cost estimates and Accreditation contract, Appointment of Lead Assessor, Preliminary visit, Appointment of assessment team, Document and records review, Assessment, Reporting, Follow up assessment, Decision, Accreditation surveillance, Renewal of accreditation, Extending accreditation, Extraordinary visits, Suspending, withdrawing or reducing the accreditation through this database and getting finally the official document of accreditation. The only condition for the customers is to have internet access, following the accreditation procedure online on the new system. DAK-MIS System will facilitate the work of DAK and $\mathrm{CABs}$ informing through this paper the CAB's and other Interested Parties about DAK-MIS database.
\end{abstract}

Keywords DAK, MIS, CABs, Accreditation, Online, Database

\section{Introduction}

The goal of this work is to facilitate hereby with
DAK-MIS System, work of DAK and other Accreditation Bodies about online accreditation process of CABs, possibilities and challenges. DAK-MIS System and online accreditation process is based on standards, regulations and guidelines which are in force in the European Accreditation (EA), International Accreditation Forum (IAF) and International Laboratory Accreditation Cooperation (ILAC).

\subsection{DAK-MIS System, Online Application Form for the Accreditation Process}

CABs [10] till now have download from the DAK webpage [3] the application for accreditation (testing [8], calibration [8], medical labs [9], inspection bodies [12], certification bodies $[13,14,15]$ etc.) have filled in and have come in DAK offices for application. When we have to establish this database CAB's (Conformity Assessment Body) will apply through the official web page of DAK [3] at the DAK-MIS button, to be registered and getting the proper information for the accreditation procedure and respective documents needed to receive the accreditation process [2] and certificate.

The process of online registering will be explained for better clarifications of CAB's in line with requests of ISO/IEC 17011:2004 standard, general requirements for accreditation bodies accrediting conformity assessment bodies [2]. DAK will organize trainings for all interesting parties regarding the use of this database. It is agreement between DAK and CAB's that it would be transition period for 2 years. On this time period it would be double documents (if they are agree), in hard copy and electronically, through database, If not CABs have to choose one solution but after two years they are obligated to apply for accreditation through database for online accreditation. The process of using of this database is: At the beginning CAB's need to be registered first at the pre-registration form fulfilling the following fields as mandatory field by field; fig. 1, fig. 2, fig. 3 and fig. 4 : 
1.1.1. Name of $\mathrm{CAB}$ (Name of the Company Interested to Receive Accreditation)

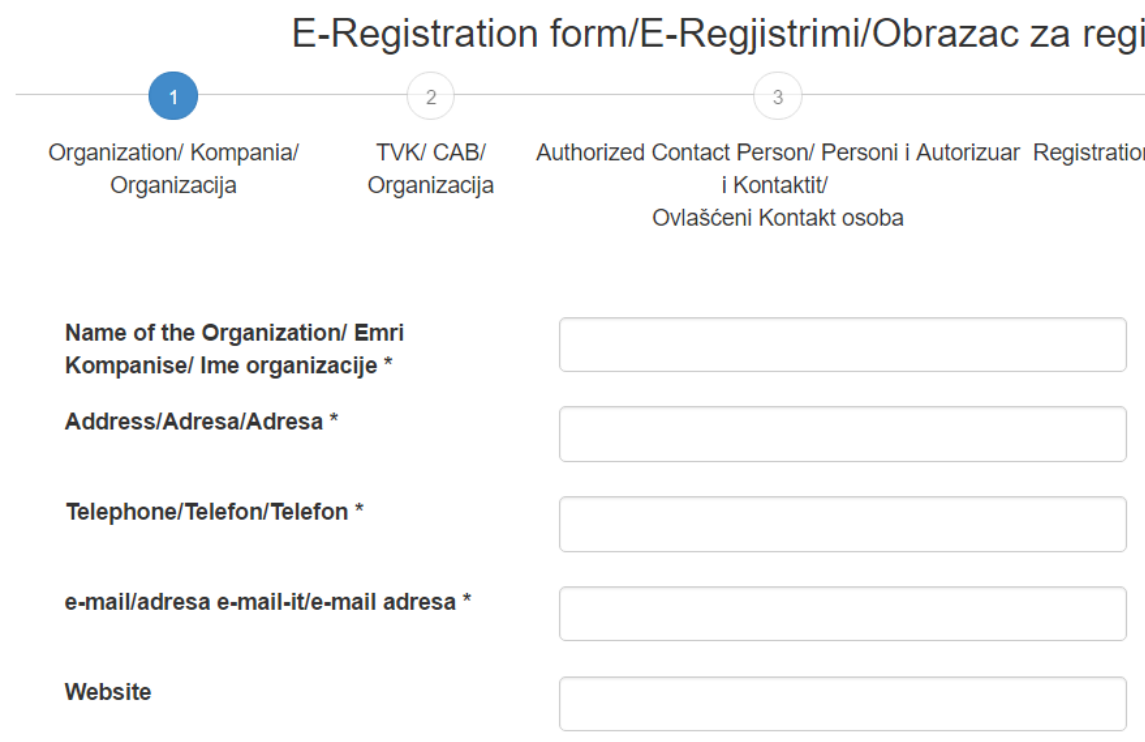

Figure 1. E-Registration form/Organization

1.1.2. Address of the Company (Official Address, Phone and Email Address)

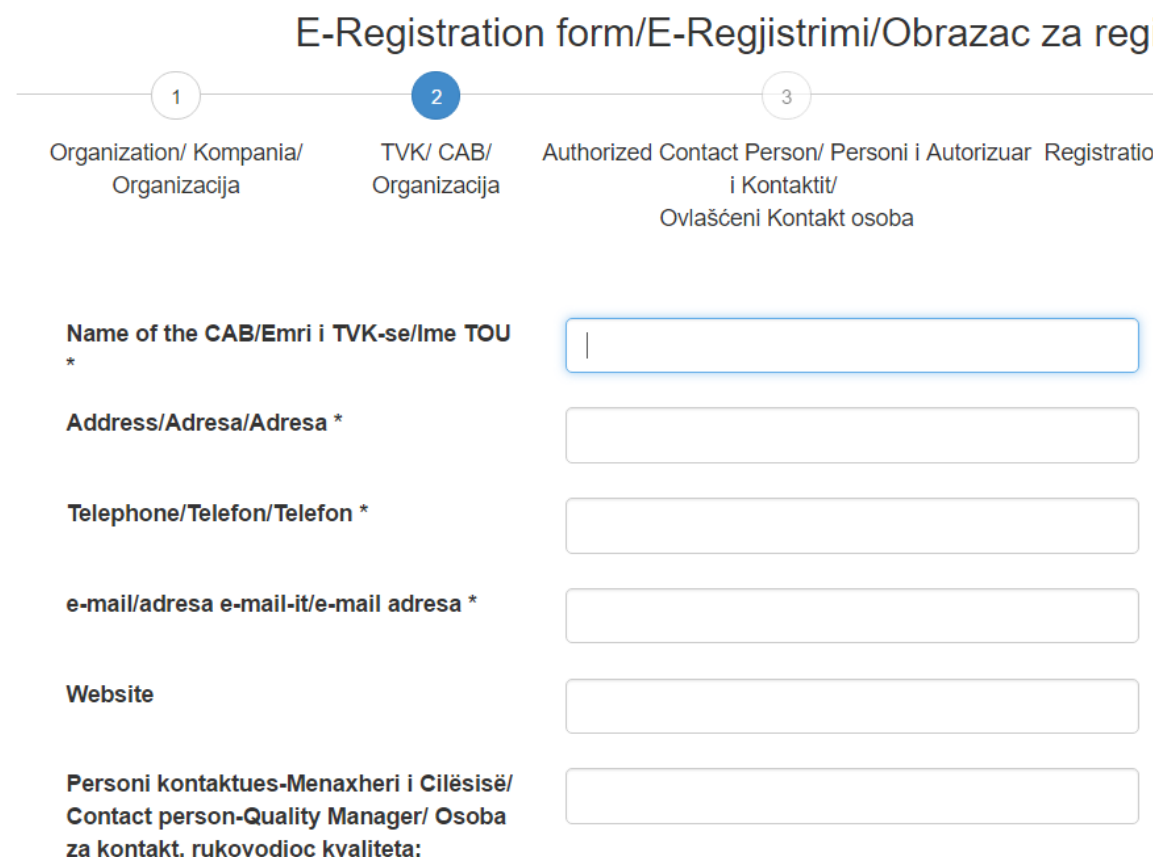

Figure 2. E-Registration form/CAB 
1.1.3. Contact Person (Phone, E-Mail Address and Upload of the Official Document of the Authorized Person from the Company)

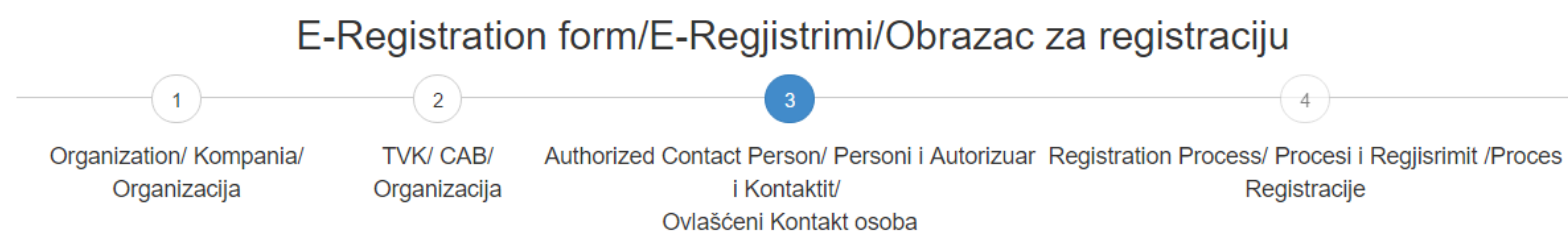

\section{- Authorized Contact Person/Personi i Autorizuar i Kontaktit/Ovlašćeni Kontakt osoba}

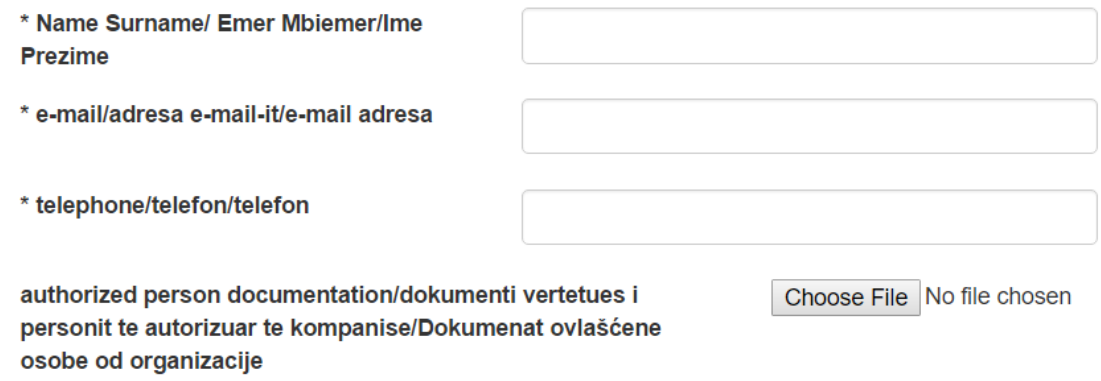

Figure 3. E-Registration form/Authorized Contact Person

1.1.4. Registration Process (Level/Type of Accreditation and Payment of the ore-registration from the bank)

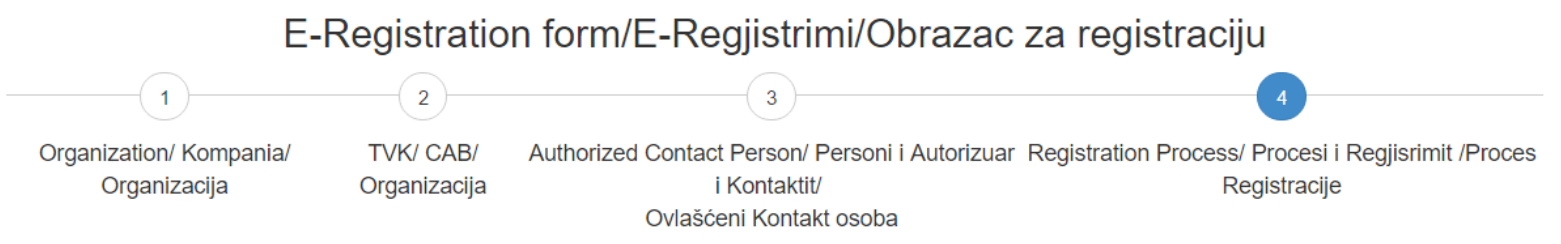

\section{Registration Process/ Procesi i Regjisrimit/Proces Registracije}

Level of accreditation applying for/Niveli i Akreditimit i kerkuar per aplikim/Nivo akreditacije Podnošenje zahteva za:

Figure 4. E-Registration form/Registration Process 


\subsubsection{Type of accreditation scope:}

a Testing / calibration laboratories [8]

b Medical laboratories [9]

c Inspection Bodies [12]

d Product Certification Bodies [15]

e Management systems Certification Bodies [13]

f Certification Bodies for persons [14]

g Others (by the new applications it would be extension of scopes)

\subsubsection{Tariff Application and CABs credentials generation:}

The application for accreditation is based on form PT-001-F01 (PT-001-F01-1, for Testing Laboratories, PT-001-F01-2 for Calibration Laboratories and PT-001-F01-3 for Inspection Bodies), and the related records and documents submitted by $\mathrm{CAB}$, are registered in the Protocol Book, form PT-001-F02, by the DAK-MIS File Manager who checks if all the forms have been submitted and the application fee was paid, according to the Administrative Instruction on Accreditation fees.

Application request tariff to be paid at the Bank before applying on-line at the DAK MIS System and to be uploaded the scanned document of the payment recipe on the official DAK-MIS System during the time of CAB filling out the request application form. After the conclusion of this process, the system will generate to the $\mathrm{CAB}$ the credentials of using the DAK-MIS System: username and password for further continuity at the DAK-MIS.

\subsection{Entering and Proceeding with DAK-MIS System-Online Application Form for the Accreditation Process}

After $\mathrm{CAB}$ will finalized the pre-registration form and get the credentials to enter at DAK-MIS system, CAB will be entered at DAK-MIS system and download the proper documents needed to follow the accreditation process called the "applicant for accreditation" [2].

In the meantime $\mathrm{CAB}$ if needed can request for an initial explanation meeting with the respective DAK-MIS officer, whereby he explains the whole accreditation procedure, fees and documents that CAB shall upload at DAK-MIS [1] for accreditation procedure. The whole general information will be found at the official website of DAK as well.

During this meeting, the $\mathrm{CAB}$ representative gets the proper and needed information that can receive at the same time the whole documentation package only electronically in DAK's webpage, and this process will not continue in hard copy at DAK offices, getting the package of documentation. They will get this information at the DAK website and in more details at DAK-MIS through credentials generated for them after fulfilling the pre-registration form.

Application Review

After application for accreditation DAK-MIS File
Manager reviews the application (using the second part B of application for accreditation) in order to check if:

- DAK is able to carry out the assessment of the applicant $\mathrm{CAB}$, in terms of its own policy (is within its declared accreditation activities),

- Has the DAK necessary competence available (suitable assessors and experts),

- Has the DAK ability to carry out the initial assessment in a timely manner.

In case any of the above mentioned aspects are not fulfilled, DAK-MIS File Manager addresses the issue in an e-mail to the manager requesting its involvement for solving the problem.

In case a qualified technical expert is not available, in exceptional circumstances, qualified technical experts from abroad will be considered.

In case is not possible to fulfil any of the aspects, manager informs the DAK-MIS File Manager by e-mail. DAK-MIS File Manager informs by e-mail the $\mathrm{CAB}$ that the application is not accepted and the reasons for not acceptance. DAK-MIS File Manager sends to the CAB part B of the application.

If all the aspects mentioned above are fulfilled the application is accepted and the accreditation process continues.

$\mathrm{CAB}$ by the application, have to send to the DAK package of documents which contains:

- The accreditation procedure, according to the $\mathrm{CAB}$ request to be accredited

- Application form, according to $\mathrm{CAB}$ request

- Administrative instruction "For accreditation fees"

- Procedures and obligations of the $\mathrm{CAB}$ based on respective standard.

The respective officer of DAK will receive the proper information from the pre-registration form filled-in from the $\mathrm{CAB}$ regarding the type of the accreditation scope, number of employees, $\mathrm{CAB}$ location and contact details and bank invoice for the payment proceed for the pre-registration process.

\subsection{Going ahead through Online Accreditation Procedures with DAK-MIS System}

The $\mathrm{CAB}$ is considered to have applied for accreditation once it has filled out electronically the pre-registration form, paid the pre-registration fee and the got the $\mathrm{CAB}$ credentials (username, password) accessing the DAK-MIS system [7] according to the respective standards and uploading the needed documentations in accordance with the standard requirements for which it is seeking accreditation.

Once it upload the full set of documentation need for the accreditation process, the $\mathrm{CAB}$ shall declare whether it wants a pre-assessment visit through fulfilling a request form for that electronically on DAK-MIS [6].

The respective accreditation officer performs: 
- The analysis of the accreditation scope requested by the $\mathrm{CAB}$

- The analysis of the technical experts listed for the assessment of the procedures

- The respective accreditation officer from DAK makes a formal evaluation process within 7 working days:

- If there are the type of non-conformities when the documents submitted by the applicant do not fulfil the requirements of the standard for which the accreditation is requested, the accreditation process will be stopped the whole documentation part will be archived on DAK-MIS [4] and the CAB will be informed officially.

- If there are type of non-conformities where proper corrections need to be done from $\mathrm{CAB}, \mathrm{CAB}$ here needs to close all the nonconformities and to upload again the documentation of undertaken corrective actions to the DAK-MIS system [4], and after the CAB will go ahead with the accreditation process.

\subsection{Contractual Agreement between DAK and CAB}

File Manager makes a cost estimate (form PT-001-F03/1 form) which includes: preliminary visit, assessment visits and issuance of certificates, in accordance with the fees foreseen in the Administrative Instruction for tariffs and sends it to the CAB.

The deadline for the approval or disapproval of the cost estimate by the $\mathrm{CAB}$ is 15 working days. After this date, the accreditation process is stopped. In such case, the documentation of the $\mathrm{CAB}$ is archived according to the procedure PM-002 [3].
If the $\mathrm{CAB}$ agrees with the cost estimate, form PT-001-F03/1, the contract is signed by $\mathrm{CAB}$ and DAK, form PT-001-F03.

- If the $C A B$ agrees with calculated costs, DAK and $C A B$ sign the agreement. This agreement will be uploaded and saved on DAK-MIS system.

- If the CAB doesn't agree the accreditation procedure is stopped and all the documentation is archived electronically on DAK-MIS.

The deadline for approval of the preliminary cost by $\mathrm{CAB}$ is 15 working days. When the deadline is over and the $\mathrm{CAB}$ requests to be accredited, the procedure will start again from the beginning. If the $\mathrm{CAB}$ accepts the calculated preliminary cost, it must pay $50 \%$ of it from this stage and $50 \%$ at the end of the process.

The respective officer of DAK prepares the approximate pre-assessment cost, fig. 5 .

This cost takes into consideration:

- Pre-assessment visit and whether foreign assessors are being used or not.

- The judgment of technical assessors relating to the duration of assessment and number of witnessing visits.

- The first cost is included in the second approximate cost. DPA sends the second cost to CAB. If CAB doesn't agree with the second cost, the accreditation procedure is stopped and documentation is archived electronically on DAK-MIS [1] [7]. If the CAB agreed with the second cost, $\mathrm{CAB}$ will pay $50 \%$ of the contracted amount before the organization of the assessment visit. The assessment visit will not be performed if the $\mathrm{CAB}$ has not paid $80 \%$ of the second invoice.

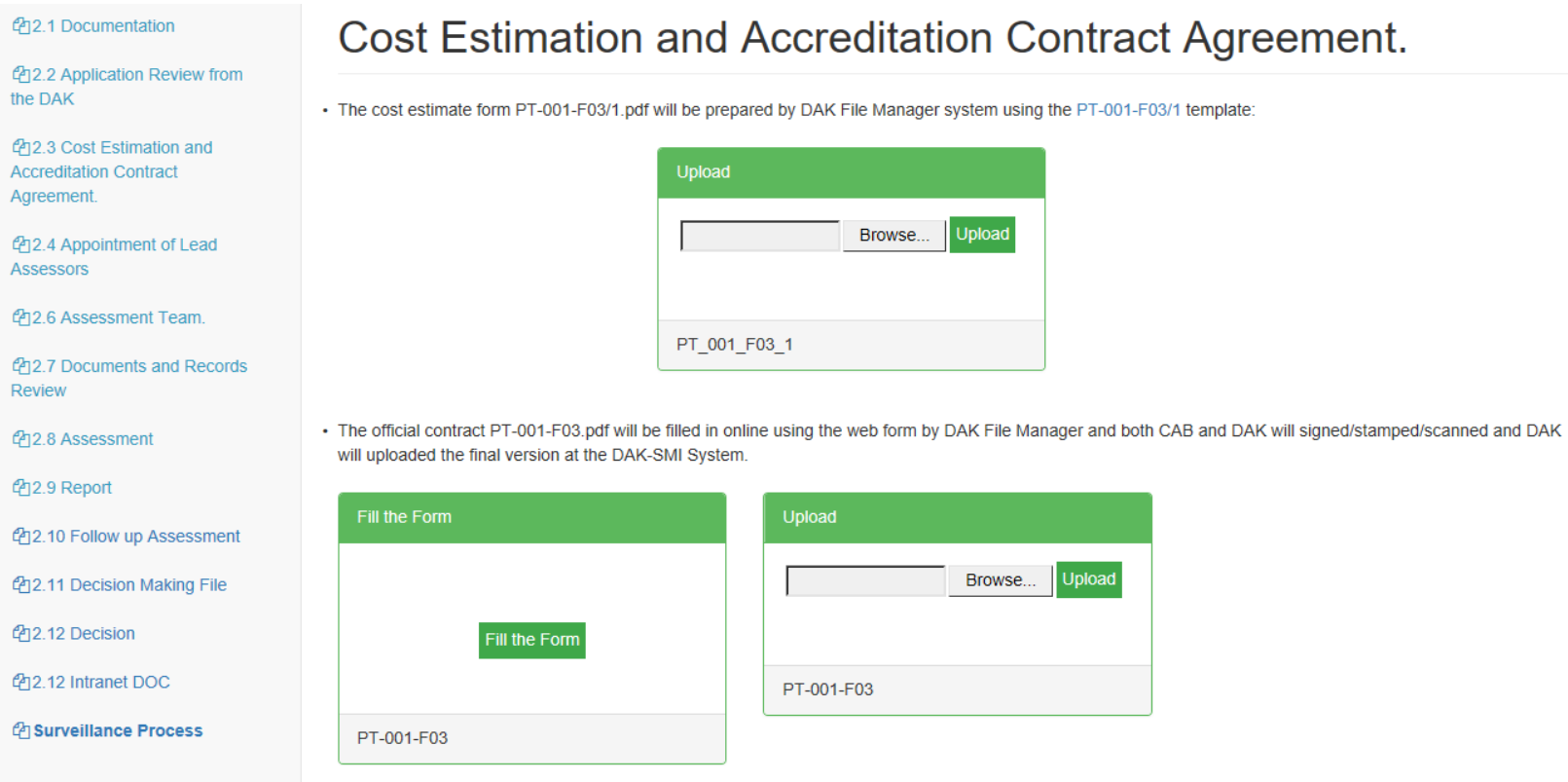

Figure 5. Cost Estimation and Accreditation Contract Agreement 


\subsection{Assessment Team}

The assessment team is appointed taking into account the accreditation standard against which the $\mathrm{CAB}$ is requesting accreditation, the technical scope submitted to accreditation.

When DAK appoint the assessment team, shall ensure that the expertise brought to each assignment is appropriate, the team as a whole shall have appropriate knowledge of the specific scope for which accreditation is sought, and shall have understanding sufficient to make a reliable assessment of the competence of the $\mathrm{CAB}$ to operate within its scope of accreditation. DAK shall ensure that team members act in an impartial and non-discriminatory manner. DAK shall inform the $\mathrm{CAB}$ of the names of the members of the assessment team and the organization they belong to, sufficiently in advance to allow the $\mathrm{CAB}$ to object to the appointment of any particular assessor or expert [2].

The Director of Accreditation Department within 7 working days from the date of submission of the formal evaluation by the respective officer of DAK, based on the analyses of recourses and decisions taken from such analysis, determines the composition of the assessment team (technical experts listed for the assessment of the procedures), fig. 6 .

Proper templates need to be generated and saved on DAK system [6] where predefined assessors/lead assessors/experts are part of this procedure. This assessment team is attached to and linked to the $\mathrm{CAB}$ applied for the accreditation process.

If the list of technical experts does not include experts that cover the scope for which the $\mathrm{CAB}$ seeks accreditation, then the respective officer of DAK informs the Director of the Directorate for Accreditation and Development to make other decisions, i.e. finding assessors/lead assessors/ experts. The use of external assessors by DAK will be done only in cases when there are no internal human resources available or when the applicant requests it. All technical experts need to be declared and entered on the DAK-MIS system [4], to be ready to create the evaluation team for the next requests for the accreditation process from different CAB's, fig. 7 .

The accreditation team need to be registered on the DAK-MIS system and updated regularly by the respective officer of DAK, and for each of them it will be generated the system credentials: username and password.

The members of the assessment team are chosen by the Director of Accreditation from the List of DAK's assessment personnel, based on their competence and related to the accreditation scope for which accreditation was requested.

This list will be shown on the CAB account of DAK-MIS system, where DAK informs the $\mathrm{CAB}$ on the composition of the assessment team and awaits the approval, in accordance with the form of notification of the names of the team participants and its approval, DAK-FO-004. The approval of the assessment team may be done electronically on the system where $\mathrm{CAB}$ representative and assessment team staff will assign the approval online on the DAK-MIS system through the proper form.

If the $\mathrm{CAB}$ agrees for the assessment team, then the procedure continues; otherwise different assessor names are proposed and the new ones proposed need to be entered on the system and finalizing and updating the new assessment team per the selected CAB. Complete or partial disapproval of the assessment team by the $\mathrm{CAB}$ shall be justified through a proper template form on the system. The final decision on the assessment team is made by the General Director of the DAK.

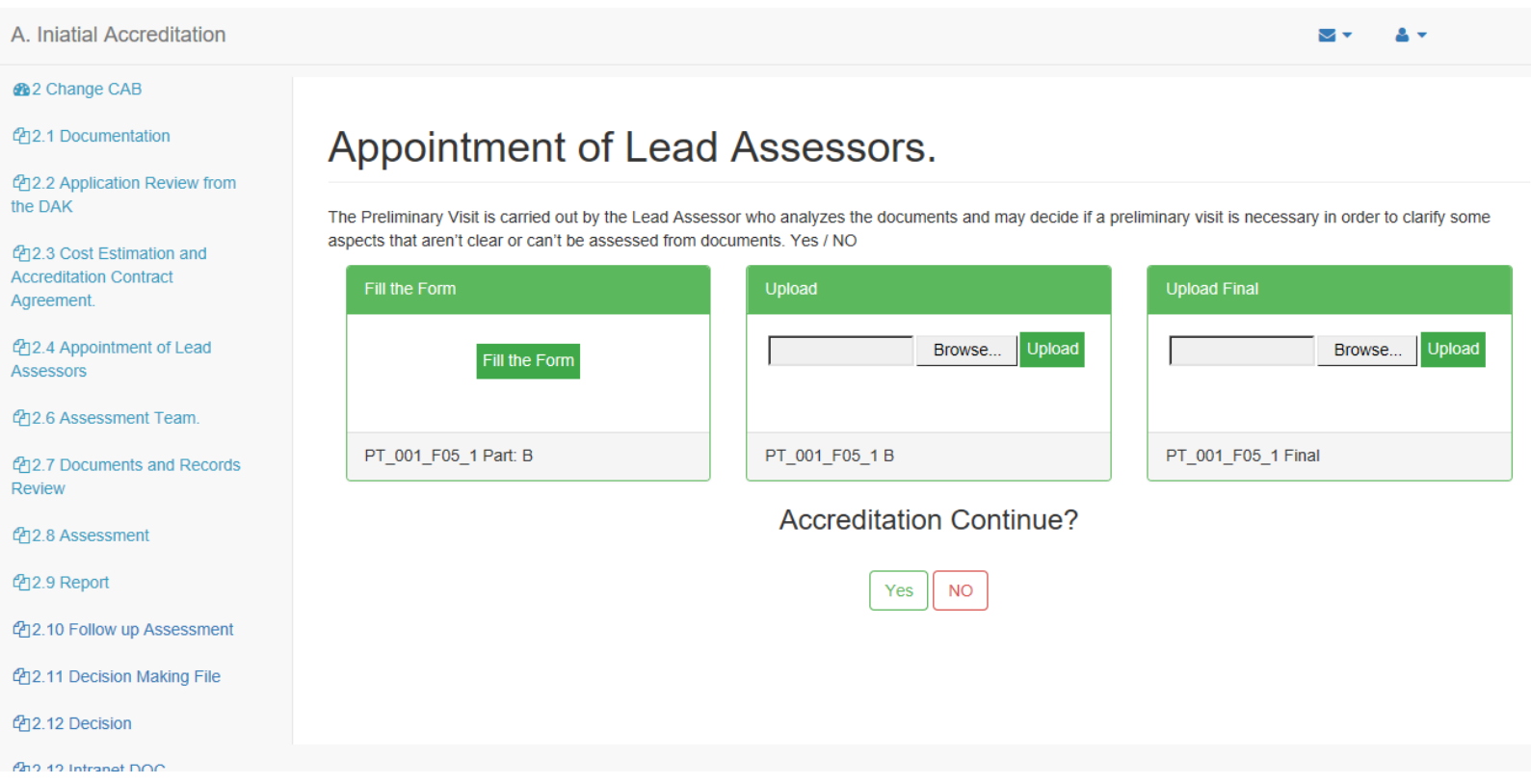

Figure 6. Appointment of Lead Assessor 


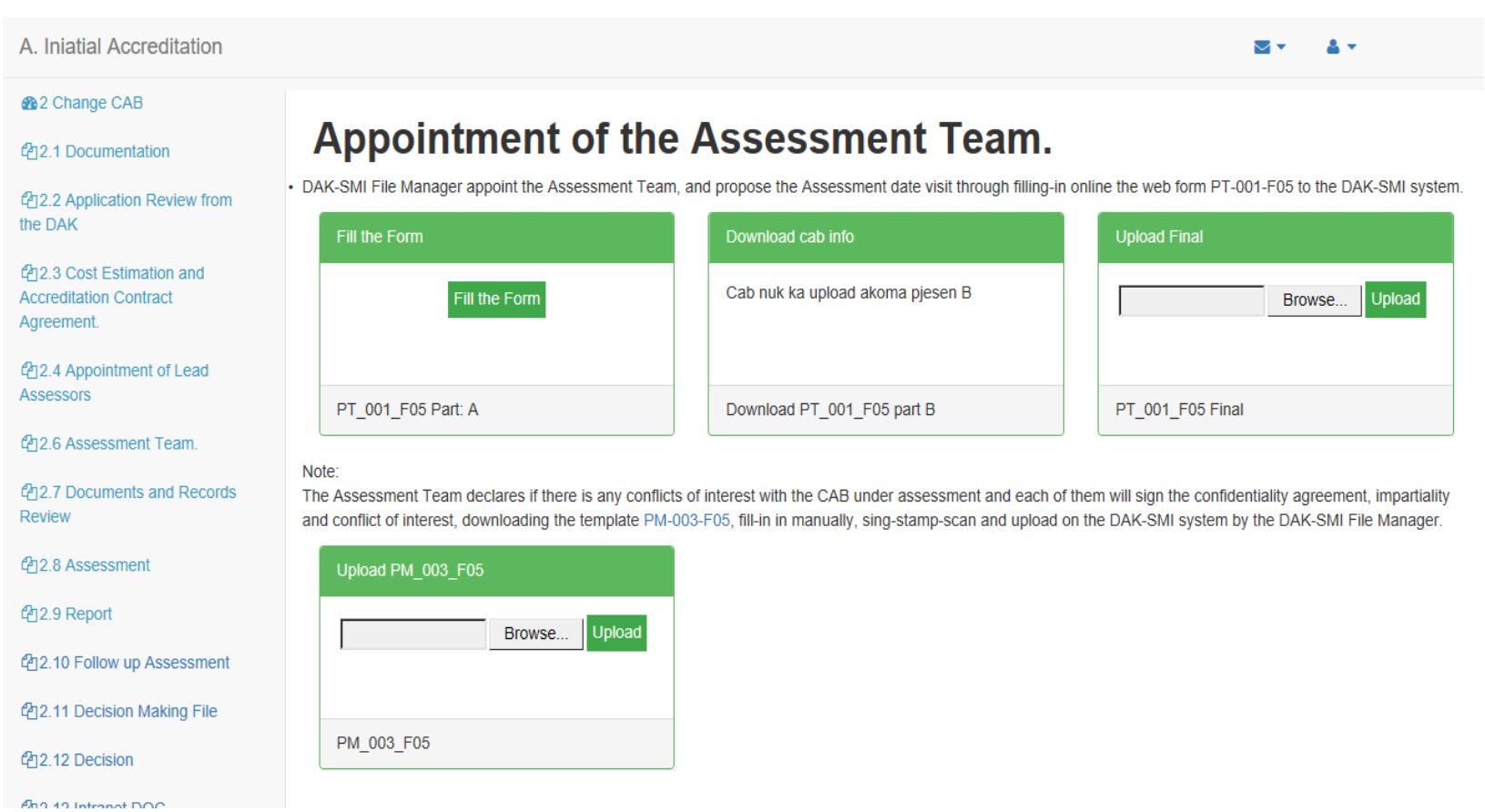

Figure 7. Appointment of Assessment Team

The assessment team initially declares to have no conflict of interest with the $\mathrm{CAB}$ under assessment and they shall sign online the confidentiality agreement, impartiality and conflict of interest.

The assessment team get access over the DAK-MIS system on the documentation of the specific CAB within 7 working days from the date of its approval through internet/intranet using assessment team credentials accessing DAK-MIS system [7].

The assessment team meets in the DAK premises, where it reviews the accreditation scope, (the list of analysis of the accreditation program), recommends a date for the assessment visit and the assessment plan.

After this meeting, the respective officer of DAK notified the $\mathrm{CAB}$ about the assessment date and attaches the notification forms such as:

- Notification Form of the assessment date and its approval;

- Assessment Plan;

All this process is done electronically on the DAK-MIS system and the $\mathrm{CAB}$ is obliged to send to DAK, within seven working days, the approval or not of the assessment plan, assessment team and the assessment date, through the electronic approval process on the DAK-MIS system.

\subsection{Assessment Evaluation Procedure}

\subsubsection{Assessment Procedure, Document Control}

The control of the documentation of the Management Systems is done by the lead assessor, who makes an assessment in accordance with the respective standard, and the technical assessor makes the technical assessment, fig. 8 .

The respective forms are filled out electronically on the
DAK System [1]:

- Check list according to the respective standard

- The lead assessor's report according to the standard requirements

- Corrective actions form

\subsubsection{Pre-Assessment, Preliminary Visit}

Preliminary visit or pre-assessment is carried out by the Lead Assessor who analyses the documents and may decide if a preliminary visit is necessary in order to clarify some aspects that aren't clear or can't be assessed from documents. In this case Lead Assessor sends an e-mail to CAB to request their agreement, specifying the date and the purpose of preliminary visit.

The preliminary visit is optional and the $\mathrm{CAB}$ has the right to decline the preliminary visit [2].

The purpose of this visit is to assess if the CAB is ready for the assessment by inspecting facilities and equipment and verifying that essential elements of the applicable accreditation standard(s) are in place.

Lead Assessor reports on all the deficiencies found during the preliminary visit, if the case. The conclusions are notified by official letter to the CAB, using the form PT-001-F04 Notification of preliminary visit conclusions.

If during the preliminary visit major deficiencies in the system of the applicant $\mathrm{CAB}$ are identified, the Lead Assessor may propose, in consultation with the DDAD, to stop the accreditation process.

The decision to stop the accreditation process is taken by the Director General of DAK and CAB is informed by official letter about the decision by the File Manager.

If the found deficiencies are not major, the $\mathrm{CAB}$ shall solve them in 3 months before the accreditation process continue with document and records review. 


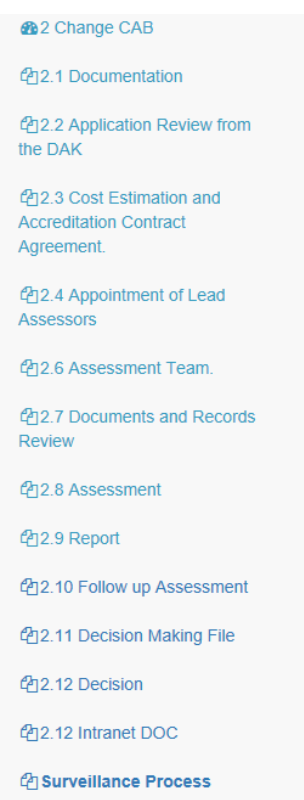

\section{Documents and Records Reviews.}

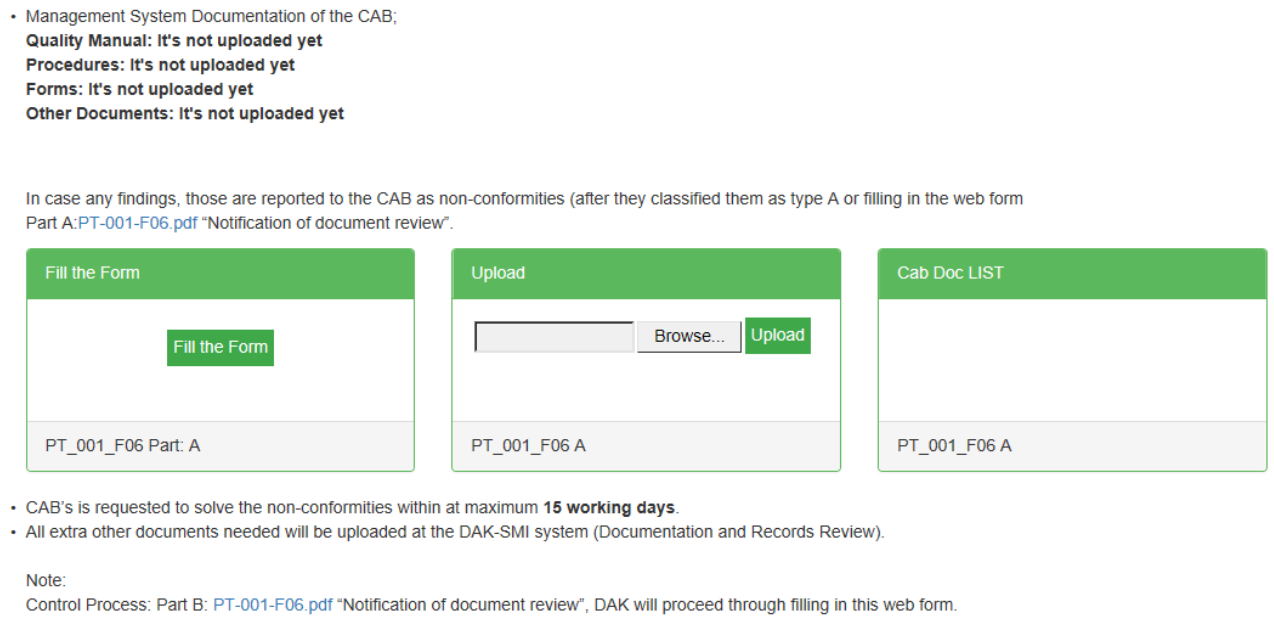

Figure 8. Documents and Records Review

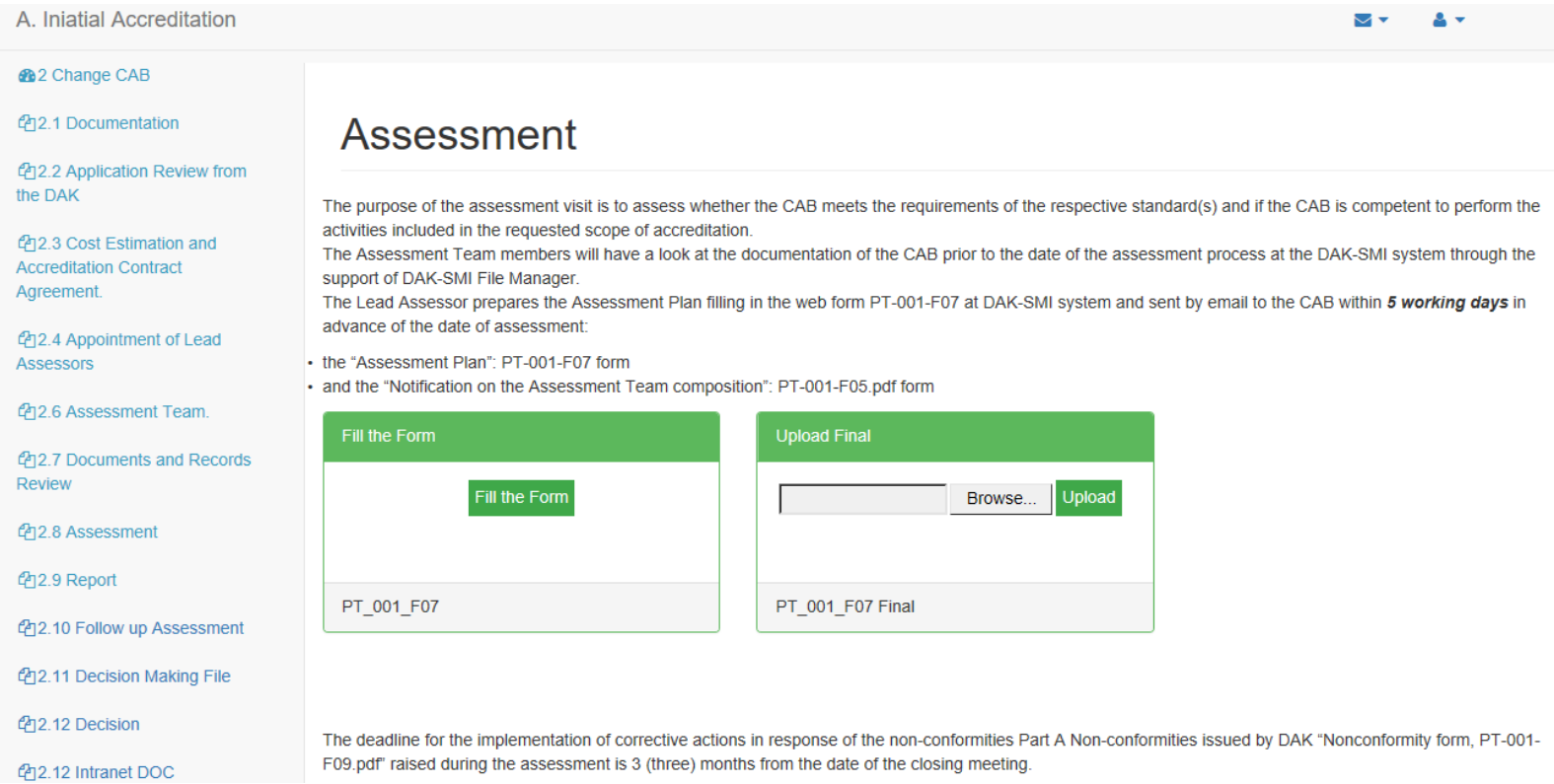

Figure 9. Assessment

\subsubsection{Assessment Visit}

The assessment process is carried out according to the procedure and requirements of standard items. The purpose of the assessment visit is to verify whether the $\mathrm{CAB}$ meets the requirements of the respective standard and verify the technical competencies already assessed during the pre-assessment and the document control, fig. 9 .

The assessment visit includes the following steps:

Opening meeting of the assessment team:

The initial meeting is done to discuss the assessment visit details and to assign the duties amongst the assessment team members. The meeting is chaired by the Lead Assessor. During this meeting the duties of each assessor and any new information are explained.
Opening the meeting with the management of the $C A B$ chaired by the Lead Assessor

The Lead Assessor is chairing the opening meeting, describing the way the assessment is going to be carried out and ensure the participants list is filled out in the opening meeting, PT-001-F08.

Assessment of the CAB's management system and technical competence

The assessment of the CAB's management system and technical competence against the applicable accreditation standard(s) will be performed by:

- Witnessing activities within the scope;

- Interviewing key personnel;

- Verifying quality records; 
- Verifying technical records;

- Verifying personnel records.

The assessment of the CAB's management system and its implementation against the applicable accreditation standard(s) is performed by the Lead Assessor. Technical assessor(s) or experts perform the assessment of the activities within the requested scope of accreditation. Technical experts will always be accompanied by a qualified assessor.

The assessment team shall complete the applicable forms:

- Checklist according to the respective standard, PT-001-F15-1 for laboratories and PT-001-F15-2 for inspection bodies, if the case;

- Assessment reports according to the standard requirements (form PT-001-F10-1 for laboratories and PT-001-F10-2 for inspection bodies);

- Nonconformity form, form PT-001-F09.

During the assessment, the assessment team will conduct internal meeting(s). An internal meeting is always conducted prior to the closing meeting. In addition, the assessment team may conduct a meeting (e.g. during lunch) to discuss the findings, if any $[2,11,16,17]$. These findings are classified according to DAK Policy DAK-PO-002.

Closing meeting with the management of the CAB chaired by the Lead Assessor

The closing meeting is chaired by the Lead Assessor. The participants in the closing meeting are the DAK assessment team members and the management of the CAB.

Lead Assessor shall ensure that the participants list is filled out in the closing meeting, PT-001-F08 [2].

Within two weeks from the assessment, the assessment team provides to the respective officer of DAK all the documents received from DAK, the assessment report according to the $\mathrm{CAB}$ and all the filled out forms, and the latter, after having reviewed the whole practice, sends the assessment report to the $\mathrm{CAB}$, which has the right to send within ten days the remarks and suggestions about the report. The respective officer of DAK cooperates with the lead assessor on whether to involve the remarks of the $\mathrm{CAB}$ in the report. The whole documentation presented in hard copy till now will be uploaded electronically on DAK System. The deadline for carrying out the corrective actions for a new $\mathrm{CAB}$ is three months.

The CAB, within the specified deadlines, shall send to DAK a report about the solutions of the nonconformities (comments, scanned document solving the non-conformities, the scanned certificates), the document will be uploaded on DAK-MIS system [6] as well. The lead assessor, in cooperation with the assessment team assesses how the $\mathrm{CAB}$ solves the nonconformities; if necessary the assessment team may send additional information to the CAB (electronically at the CAB account space on the DAK System).

For failure to solve the nonconformities, the CAB may ask to postpone the deadline for carrying out the corrective or preventive actions only once. The request to postpone the deadline is done through the DAK System fulfilling the proper form electronically. The respective officer of DAK approves or not the postpone process which cannot be more than one month and the proper document will be uploaded on DAK-MIS System.

In case the $\mathrm{CAB}$ does not solve the nonconformities within the deadline, then the lead assessor requests the initiation of the rejection procedure of the accreditation of the unsolved nonconformities. If the $\mathrm{CAB}$ has solved the nonconformities, the lead assessor reports electronically on DAK System fulfilling the form, fig. 10.

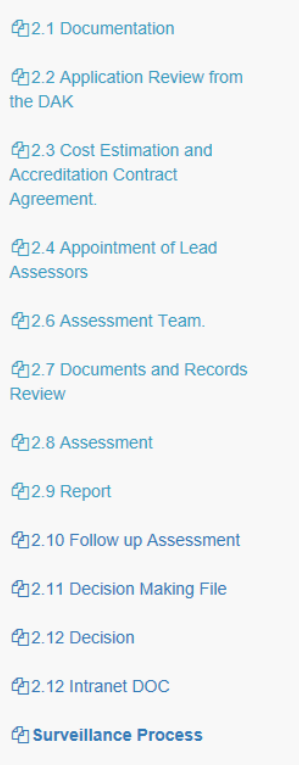

\section{Report}

The following text needs to be entered at DAK part: Within 15 working days from the assessment, the Assessment Team shall conclude and upload to the DAK-SMI system all manually completed documents used for the assessment report according to the CAB type:

- Assessment report for Testing \& Calibration Laboratories PT-001-F10-1.pdf

- Assessment report for Inspection Bodies PT-001-F10-2.pdf.

The DAK-SMI File Manager sends the assessment reports to the CAB by email, and be accessed and upload them through the DAK-SMI system.

The CAB has the right to send remarks and suggestions about the report within 5 working days and fill-in manually using Part B: PT-001-F10-1.pdf or Part B: PT001-F10-2.pdf.

The following text needs to be entered at CAB part:

Within 15 working days from the assessment, the Assessment Team shall conclude and upload to the DAK-SMI system all manually completed documents used for the assessment report according to the CAB type

- Assessment report for Testing \& Calibration Laboratories PT-001-F10-1.pdf
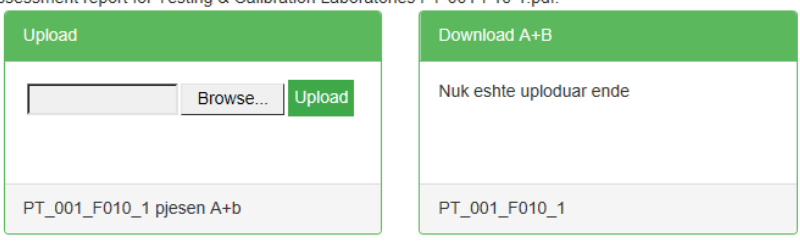

Upload Final

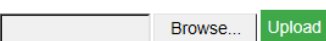

The DAK-SMI File Manager sends the assessment reports to the CAB by email, and by the DAK-SMI system. The CAB has the right to send remarks and suggestions about the report within 5 working days and fill-in it manually using Part B: PT-001-F10-1.pdf or Part B: PT001-F10-2.pdf.

Figure 10. Report 
The respective officer of DAK, after reviewing the practice of the conclusion of nonconformities, provides the whole above-mentioned documentation to the Accreditation Council, for analysis of the assessment reports, the conclusion of the nonconformities found during the assessment procedure. The respective officer of DAK conducts the proper preparations for the meeting of the Accreditation Council (AC). After reviewing the documentation, the Chairman of the AC proposes to the DAK Director to render a decision, by making a report, fulfilled electronically should be saved on the DAK-MIS System. In the DAK-MIS system should be entered all (around 30) members of the Accreditation Council and should be generated all credentials to access the DAK-MIS system [7] to check and control the proper documentation part (from $\mathrm{CAB}$ and from assessment team) of the proper
$\mathrm{CAB}$ which under the accreditation process.

\subsection{Decision}

The respective officer of DAK, after having reviewed the materials electronically on the DAK-MIS System submitted by the assessment team, the assessment report and the proposals of the Accreditation Council, renders the final decision for the accreditation of the $\mathrm{CAB}$, this document as well will be saved on DAK-MIS System [2].

Director of DAK shall render a decision, fig. 12, within 15 working days from the date the documentation was presented to him. Director of DAK fills out the respective form and sends it to the respective officer of DAK for the notification of the $\mathrm{CAB}$, about the accreditation decision the whole notification process is done electronically as well through the DAK-MIS System to the CAB, fig. 11.

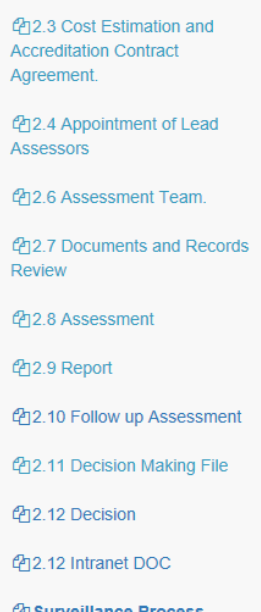

th Surveillance Process

\section{Decision Making File}

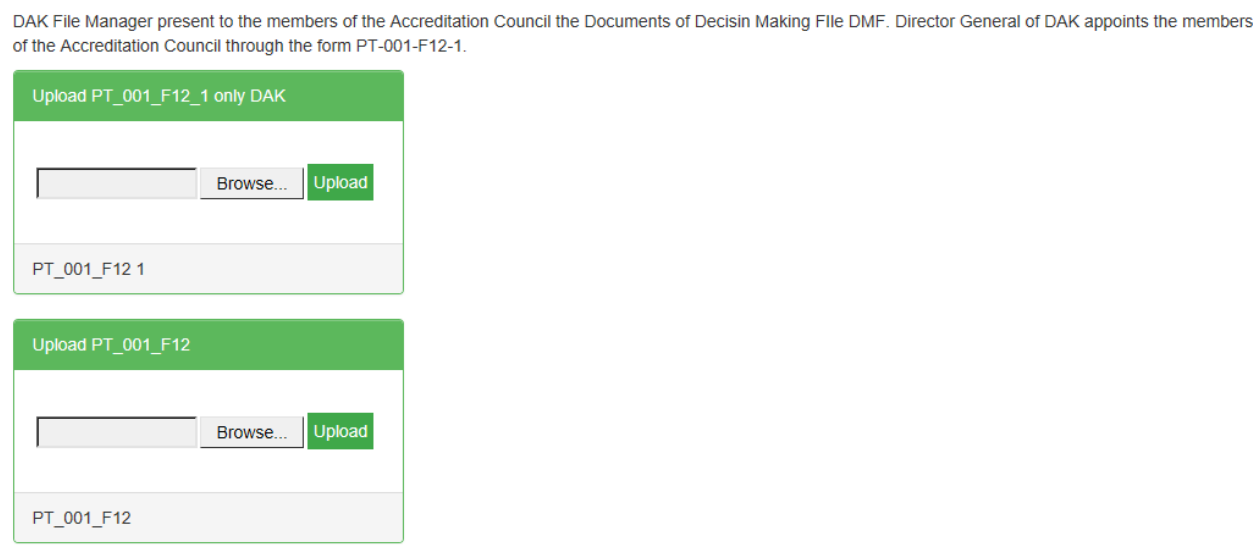

When all nonconformities are closed out, the DAK-SMI File Manager, after receiving the records from the Lead Assessor, prepares the decision making file (DMF) and fills in the Summary of Accreditation process document

Figure 11. Decision Making File

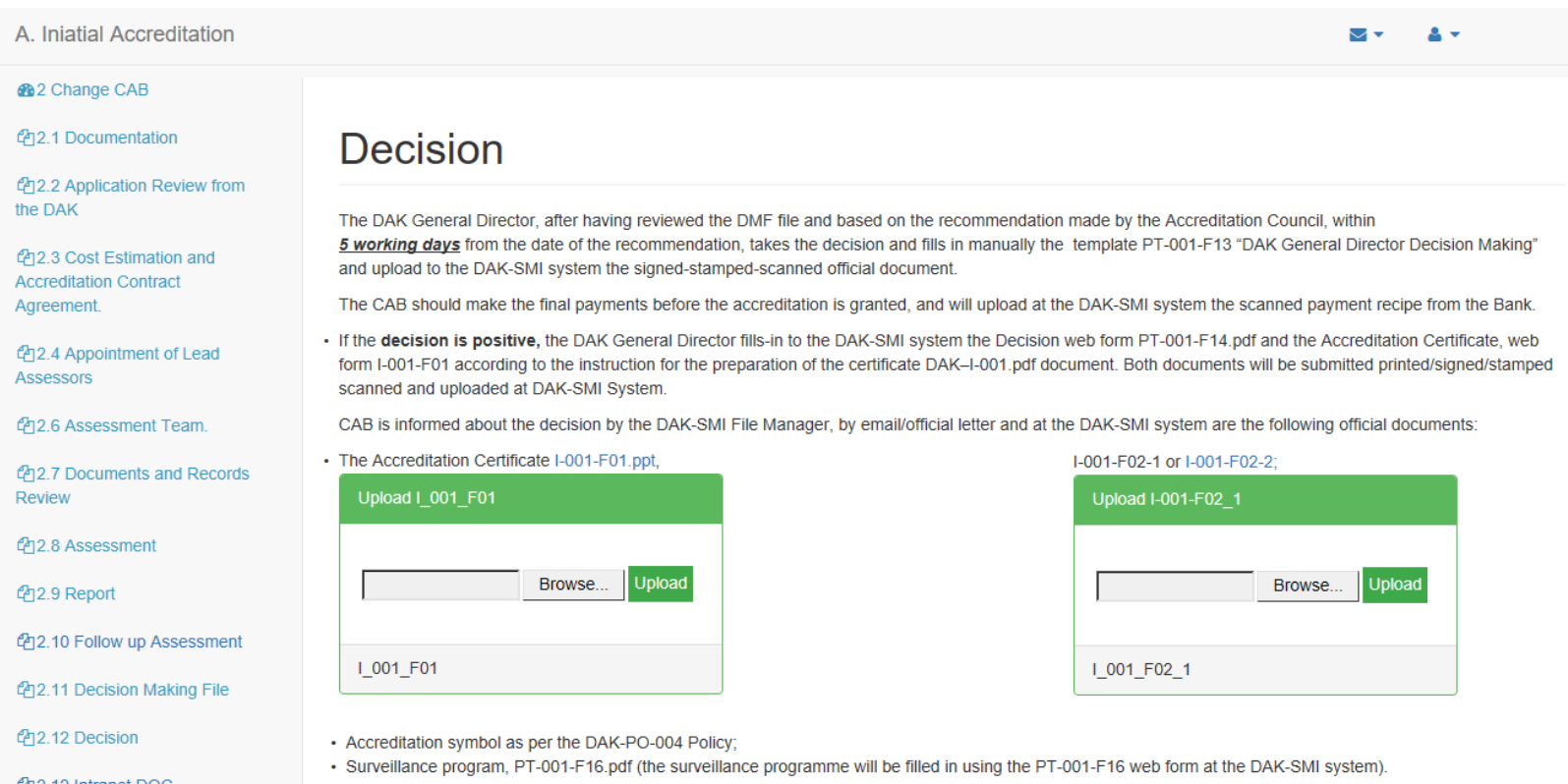

Figure 12. Decision 
If the decision is positive, then the procedure for compiling the certificate is carried out, according to the respective procedure (this process will be done in DAK-MIS System as well). The CAB receives within 7 working days electronically by DAK-MIS system and in hard copy as well [2]:

- The Accreditation Certificate, including the annex of the accreditation scope

- Rights and obligations of CAB procedure

- Copy of assessment report

- Procedure for using the accreditation symbol

In the end, the $\mathrm{CAB}$ is issued the final financial invoice on what it shall pay (the certificate and other additional actions that may have been carried out during the accreditation procedure). The accreditation is valid for a period of four years. The whole payment recipe and other documents will be downloaded on DAK-MIS system as well.

If the decision is negative, the $\mathrm{CAB}$ is informed of the rejection of accreditation (electronically and officially) and it is informed of its right to appeal to the Professional Council. The CAB may appeal within 14 days from the date of notification of the rejection. After the CAB files the appeal in the offices of DAK, the appeal procedure with the Professional Council (PC) is followed.

The whole documentation, irrespective of the decision, is forwarded to the respective officer, who reviews the file and the documents and then sends it to the Quality Manager for protection according to the respective procedure of record control [2]. The whole process is going through the archiving process as well in DAK System based on the procedure of record control as well. The Accreditation Directorate places the accredited CAB-s in the list of accredited entities in DAK's webpage. From the DAK-MIS System [7] the announced to the DAK web page goes automatically.

\subsection{Accreditation Surveillance}

During an accreditation cycle (4 years) DAK carries out 4 assessment surveillances [2]. DAK will perform the first surveillance no later than 12 months after the initial accreditation was granted and the subsequent surveillances every year.

The last surveillance (S4) becomes reassessment in case the $\mathrm{CAB}$ submits the application for renewal of accreditation with 6 months in advance of the expiry date of the accreditation certificate.

The File Manager together with the Lead Assessor prepares the surveillance program of the CAB (PT-001-F16) for each calendar year from the time the $\mathrm{CAB}$ was accredited or re-accredited. The surveillance program includes the witness assessments that shall be undertaken by the accreditation body. In each accreditation cycle the full scope of the $\mathrm{CAB}$ will be assessed.

The Director of Accreditation and Development Direction appoints the assessment team that will conduct the surveillance assessment.
Before each surveillance visit DAK informs the $\mathrm{CAB}$ on the assessment plan and date of the visit, in order to receive its approval. At the same time, DAK sends to $\mathrm{CAB}$ its cost estimate.

The surveillance visit is conducted in a similar way as the initial assessment visit, but is less comprehensive.

During each surveillance visit, at least the following areas will be assessed:

- The effectiveness of the corrective actions taken in response of nonconformities raised during the last DAK visit

- Changes made to the management system

- Changes within the organization and/or, if applicable, the mother organization

- Changes of key personnel

- Participation in PT/ILC and the results obtained (for laboratories)

- Internal audits

- Management review

- Complaints and (if applicable) appeals

- Corrective action

- Quality control (for laboratories)

- Reporting

- Use of the DAK accreditation symbol

The reporting process for surveillance visit is the same as for initial assessment visits.

The corrective action process for surveillance visit is the same as for initial assessment visits, with the exception that for the corrective actions shall be implemented within 2 (two) months after the closing meeting.

The DAK General Director confirms the continuation of accreditation based on the documents provided by the assessment team, using form PT-001-F13. File Manager inform the $\mathrm{CAB}$ on the continuation of accreditation by e-mail.

\subsection{Renewal of Accreditation}

No later than six months before the accreditation expires, the $\mathrm{CAB}$ shall file a request for renewal of accreditation to DAK if it wants to continue its accreditation [2]. Upon receiving the request for renewal of accreditation (PT-001-F01), DAK initiates the process of renewal of accreditation which is a similar process as for the initial accreditation, with the exception that a preliminary visit is not conducted, as mentioned above.

\subsection{Extending Accreditation}

The extending of accreditation is carried out similarly as the initial accreditation process [2].

Usually, the extension assessment is performed with the next planned surveillance visit.

The assessment for extending accreditation is not carried out unless the $\mathrm{CAB}$ is paying the invoice sent by $\mathrm{DAK}$ for the respective assessment. 
The General Director may take the following decisions, based on the recommendation of the Accreditation Council:

- Extending of accreditation;

- Partially extending of accredited scope;

- Not granting the extending of accreditation.

General Director informs the $\mathrm{CAB}$ on the decision, through the File Manager. In case of a negative decision the $\mathrm{CAB}$ shall be informed on the reasons that lead to the respective decision.

The extension of accreditation is granted within the same validity period of accreditation certificate issued initially.

\subsection{Extraordinary Visits}

DAK may conduct extraordinary visits (unplanned) in cases when the continuity of the fulfilment of the requirements of the applicable accreditation standard(s) is suspected to be breached [2].

Extraordinary visits are carried out in the following situations: there are changes in the CAB's legal entity status, changes of the CAB's organizational structure or within its mother organization, changes in resources and premises, changes of the scope of accreditation, complaints from the authorities, clients or users, etc.

These additional visits are organised in the same manner as regular surveillance visits.

Following the extraordinary visits, depending on the non-conformities found, the team may propose in the report:

- To raise non-conformities and allow the CAB 2 (two) month to solve the non-conformities;

- To directly suspend: part or the whole scope of accreditation of the $\mathrm{CAB}$.

\subsection{Suspending, Withdrawing or Reducing the Accreditation}

DAK suspends the accreditation of a $\mathrm{CAB}$ in the following situations:

At CAB's request due to temporary inability to carry out its activities under the accreditation - $\mathrm{CAB}$ may request to DAK to suspend totally or partially its accreditation, for a period of maximum 6 month.

In this case, the $\mathrm{CAB}$ requests the suspension in writing specifying:

- The scope of accreditation for which suspension is requested;

- The situations making the body to be unavailable which lead to failure in meeting the accreditation requirements;

- The necessary measures for improving the respective situation.

- Date when the suspension requested by the $\mathrm{CAB}$ starts.

In the below mentioned situations, suspending a part or all the accreditation scope of an accredited CAB - for a period of maximum 6 months:
- Not solving the non-conformities on time as foreseen in DAK's documents;

- In case of a complaint after an extraordinary visit;

- When the CAB does not agree with the surveillance/ extraordinary assessments, according to DAK 's established rules;

- Incorrect reference to accredited status misuse of the symbol of accreditation or of the reference to accredited status;

- The fees were not paid according to the contract.

The recommendation is made by the Accreditation Council and based on the recommendation the General Director makes the decision. The CAB is notified by General Director of DAK, through File Manager, on the suspending decision. The official notification includes the accreditation scope for which the suspension was applied and the reasons for suspension, as well as the conditions for lifting the suspension.

$\mathrm{CAB}$ can appeal the decision on suspending the accreditation, according to DAK's Procedure on Appeals, code DAK-PM-006.

During the suspension period the $\mathrm{CAB}$ shall not issue any reports or certificates under accreditation and shall not make reference to its accreditation status or use the accreditation symbol for the scope for which it was suspended.

The person who is in charge with maintenance of DAK's website publishes on website the sanction taken.

During the accreditation suspension period:

a) the expiry data of the accreditation certificate remains the same;

b) all the contractual obligations of the $\mathrm{CAB}$ remains in force;

c) The CAB is maintained in the list of accredited bodies on DAK's website, but marked as suspended;

d) The $\mathrm{CAB}$ shall inform its clients that the respective activities are no longer covered by accreditation.

The accreditation suspension is lifted as soon as the $\mathrm{CAB}$ demonstrates the fulfillment of the accreditation requirements based on the evidences of solving the non-conformities which led to the decision of suspension.

The decision for lifting the suspension is made by General Director of DAK based on the recommendation of the Accreditation Council, based on the proposal of the LA.

The validity period of the certificate remains the same after the suspension is lifted.

DAK reduce or withdraw the accreditation of a $\mathrm{CAB}$ in the following situations:

a) At CAB's request, specifying:

- The accreditation scope for which is requested the withdrawal /reducing of accreditation;

- The situations leading to not meeting the accreditation requirements;

- Date when the reducing/withdrawal requested by the $\mathrm{CAB}$ starts. 
b) In the below mentioned situations, reducing/withdrawing accreditation of an accredited CAB:

- When the CAB does not fulfill, repeatedly, any of the accreditation requirements, as they are mentioned in the accreditation contract and DAK documents;

- If the $\mathrm{CAB}$ could not demonstrate the solving the situation for which was suspended (6.16.1.1 b));

- In case DAK finds out that an accredited CAB provided intentionally false information or deliberately breached the accreditation rules.

The CAB is notified by General Director of DAK on the reducing/withdrawal of accreditation decision and the reasons behind the decision. The official notification includes the accreditation scope for which the reducing of accreditation was applied.

$\mathrm{CAB}$ can appeal the decision on reducing/withdrawal the accreditation, according to DAK's Procedure on Appeals, code DAK-PM-006.

Since the moment DAK took the reducing/ withdrawal decision, the $\mathrm{CAB}$ shall not issue any reports or certificates under accreditation and shall not make reference to its accreditation status or use the accreditation symbol for the scope for which it was reduced/ withdrawn.

The person in charge with maintenance of DAK's website:

- Publish the accreditation certificate following the reducing of accreditation;

- Withdraw from the website the accreditation certificate in case of withdrawal of accreditation.

\section{Benefits and Disadvantages from Online Accreditation}

Today, the world economy is under the strong influence of globalization processes and has become flexible, open and integrated. Internet, many aspects of our life have had transformed. Using online DAK-MIS application system may be cost-effective and straightforward for Accreditation Bodies. It is example of small companies or Accreditation Bodies in the early beginning, allowing them to expand their offers and services. Now, all we need is computer and internet connection. Applying for accreditation online doesn't need to worry about fulfilling in error-free hard-copy forms and other documents, spending time money on postage to return them. There are other benefits like knowing an application it has been safely received by DAK or CABs, confirmation at the end of the application process. Online DAK-MIS application system provides clients with a facility to save their work and time.

Disadvantages of online DAK-MIS application system for DAK, Accreditation Bodies and CABs may be at the time when there occur more and more requests at time which gets difficult to handle it. In case of hardware failures, online
DAK-MIS application system, clients get in trouble and their online transactions get affected. Online DAK-MIS application system is atomicity. Atomicity ensures that if any step of online DAK-MIS application system fails in the process of the transaction, the entire transaction must failed. After that all of those steps have to be repeated again.

Accreditation is confidence but by online DAK-MIS application system, personal information and other data for Accreditation Bodies and CABs, online sometimes can present a security risk for them.

DAK staff is small in number and by increasing the number of accredited Conformity Assessment Bodies (CABs) the volume of work has been increased. It's forecasted that by increasing the volume of work more and more Going LIVE with DAK-MIS system will be a necessity as well and it would be possible implementation of all activities on the accreditation process of CABs.

Due to implementation of DAK-MIS System, it would be reduced considerably the volume of work and accreditation costs. Until now representatives of CABs for every document and other activities has to come physically to the DAK offices, now through this web application all activities will be performed by the location of the $\mathrm{CAB}$, by the only condition, having access on the internet. The Web Application/Database for online accreditation DAK-MIS, has a crucial importance for fulfilment of the requirements of DAK customers and other Accreditation Bodies. We keep into consideration that usage of the DAK-MIS System will allow DAK to use the same number of staff, as per the unable capabilities on increasing of the DAK budget as per increase request on the DAK Staff which will be not possible. This database it would be very important instrument for quality work and helpful for surviving small Accreditation Bodies as ours.

\section{Conclusions}

As per requirements, DAK shall improve and update the actual official Web Page and develop further the DAK-MIS System IT Application for managing the whole accreditation process online even though there are difficulties on missing the digital signature law and infrastructure to be implemented. The future DAK-MIS fully integrated system with all Accreditation Processes needs to be developed to the second phase of DAK-MIS System implementation. The $1^{\text {st }}$ Part: "Initial Accreditation Process" is fully online including: E-Registration Form; Log in- Accreditation Process; Main Menu of DAK-MIS and Documentation: Documents, Rules and Standards; Application Fill-in; Application Review; Cost Estimation and Accreditation Contract Agreement; Personnel Database; Appointment of Lead Assessors; Preliminary Visit; Appointment of the assessment team; Documents and Records Review; Assessment; Report; Follow up Assessment and Decision. $2^{\text {nd }}$ Part of Surveillance and Renewal of Accreditation need to be developed on the second Project online Application as the $1^{\text {st }}$ Development of 
the System supporting the digital signature process and getting interface with the standardization system as well.

\section{Acknowledgements}

We would like to thank our colleagues from DAK which have to implement DAK-MIS and experts from the Accreditation Bodies as part of European co-operation for Accreditation in their experiences in accreditation process and implementation of ISO/IEC 17011 General requirements for accreditation bodies accrediting conformity assessment bodies.

\section{REFERENCES}

[1] ISO/IEC 27001, specifies requirements for an information security management system (ISMS);

[2] ISO/IEC 17011, General requirements for accreditation bodies accrediting conformity assessment bodies;

[3] http://dak.rks-gov.net;

[4] "Learning Zone-MIS: Time to plunge into automated systems." Printing World. 6 April 2006;

[5] Shim, Jae K. and Joel F. Siegel. The Vest Pocket Guide to Information Technology. John Wiley \& Sons, 2005;
[6] Thomas Connolly and Carolyn Begg, Database Systems, 2005, PP 358-360, ISBN 032121025 5;

[7] Kenneth C. Laudon, Jane P. Laudon, 2014, Management Information Systems.

[8] ISO/IEC 17025, General requirements for the competence of testing and calibration laboratories;

[9] ISO/IEC 15185, Medical laboratories, Requirements for quality and competence;

[10] ISO/IEC 17000, Conformity assessment — Vocabulary and general principles;

[11] ISO 19011, Guidelines for auditing management systems;

[12] ISO/IEC 17020, Conformity assessment - Requirements for the operation of various types of bodies performing inspection;

[13] ISO/IEC 17021, Conformity assessment - Requirements for bodies providing audit and certification of management systems;

[14] ISO/IEC 17024, Conformity assessment - General requirements for bodies operating certification of persons;

[15] ISO/IEC 17065, Conformity assessment - Requirements for bodies certifying products, processes and services;

[16] ISO 9001, Quality management;

[17] ISO/IEC Guide, International vocabulary of metrology - Basic and general concepts and associated terms (VIM). 